\title{
The determinants of stadium attendance in elite women's football: Evidence from the
}

\section{UEFA Women's Champions League}

\author{
Maurizio Valenti ${ }^{1}$, Nicolas Scelles ${ }^{2}$ and Stephen Morrow ${ }^{1}$ \\ ${ }^{1}$ University of Stirling, Faculty of Health Sciences and Sport, Stirling, Scotland. \\ ${ }^{2}$ Manchester Metropolitan University, Department of Economics, Policy and International \\ Business, Manchester, England.
}

\begin{abstract}
Women's football struggles to build a solid platform in terms of fan interest. However, while an increase in gate receipts can help assist its long-term sustainability, there is limited evidence in the academic literature on the factors influencing spectator demand in women's football. The authors investigate determinants of stadium attendance for UEFA Women's Champions League (UWCL) matches. Using regression models deployed on 554 UWCL games played between $2009 / 10$ and $2017 / 18$, the authors examine contextual and sport-related variables as the main predictors of stadium attendance. Findings show that there is no continuous growth of attendance over the period examined, and highlight that spectators' interest is positively associated with five factors: stage of the competition, uncertainty of match outcome, competitive intensity, away club's reputation and weather conditions. Football governing bodies should put in place initiatives to ensure match outcome uncertainty is maintained as this represents a key determinant to maximise stadium attendance. Based on the specific context of European women's football, recommendations to foster its development are discussed. These include incentivising investment into the elite women's game and designing sport policies to encourage participation at grassroots levels.
\end{abstract}

Keywords: Attendance; Demand; Fan behaviour; Spectators; Women's football. 


\section{Introduction}

The promotion of women's football has recently emerged as a key priority in the agenda of international football governing bodies (FIFA, 2014, 2016; UEFA, 2017a). However, while participation rates and investments have increased dramatically in the last 25 years (FIFA, 2014; UEFA, 2017a), the lack of consistent spectator demand continues to be one of the strategic challenges that women's football currently faces.

Owners and executives of women's clubs have expressed their concerns regarding the increasing costs and the concomitant lack of revenues (e.g. ticketing, broadcasting) available to women's clubs (ECA, 2014), thus raising scepticism over the possibility that women's football can become financially sustainable in the near future (Allison, 2016; Meier, Konjer \& Leinwather, 2016; Southall, Nagel \& Le Grande, 2005). In practice, the financial structure of women's football clubs resembles that of men's amateur clubs, where the major sources of income come from private donations and subscriptions, with a much less substantial contribution from prize money and gate receipts (ECA, 2014; FIFPro, 2017). Therefore, the constraining financial situation of the women's game highlights a crucial need for women's clubs to generate further revenue from all sources, including match day attendance.

Although stadium demand may have common features across various sports, there are likely to be substantial differences between men's and women's activities. In particular, football represents a platform for the social construction and presentation of hegemonic masculinities, which contributes to emphasise logics of gender dominance both on and off the field (Pfister, 2015). This has influenced the history, popularity and development of women's football in many countries, thus also affecting its overall positioning in the professional sports market. Hence, while attendance demand has been extensively researched in men's football (e.g. García \& Rodríguez, 2009), results cannot necessarily be generalised and applied to the women's game. 
In the literature, an extended scholarly discussion has considered the consumption of sport events (e.g. Andreff \& Scelles, 2015; Pawlowski \& Anders, 2012; Scelles et al., 2013, 2016). However, the debate has mainly focused on men's elite sports (e.g. Coates, Humphreys \& Zhou, 2014), while research on women's sports has concentrated on elements related to both fan motivation (Funk, Ridinger \& Moorman, 2003) and (the lack of) TV coverage (e.g. Cooky, Messner \& Hextrum, 2013). A specific focus on women's football fandom was drawn from sociological (e.g. Guest \& Luijten, 2017) and marketing (Hallmann, 2012; Southall et al., 2005) disciplines. Yet determinants of women's football stadium attendance have been less commonly investigated from a sports economics perspective, with only two studies having explored demand in the German (Meier et al., 2016) and US (LeFeuvre, Stephenson \& Walcott, 2013) domestic leagues. More robust empirical evidence about women's football stadium attendance is therefore needed to guide stakeholders' managerial and policy actions focused on the future viability of the women's game.

To study demand in women's football, we have compiled a dataset comprising gamelevel attendance from the top European competition for elite women's football clubs, i.e. the Union of European Football Associations (UEFA) Women's Champions League (UWCL), between $2009 / 10$ and $2017 / 18$. The particular focus on this competition is primarily due to the availability of information regarding a fundamental predictor of demand such as (a priori) uncertainty of outcome. In addition, this study can contribute to the on-going debate between the ECA (European Clubs Association) and UEFA over possible changes designed to improve the current format of this competition (ECA, 2018). Moreover, while previous studies of attendance in women's football have analysed individual leagues (LeFeuvre et al., 2013; Meier et al., 2016), this paper considers a competition involving teams from different nations. This allows us to explore the demand for women's football across various settings, in line with one 
of the objectives of international football governing bodies to foster the growth of women's football worldwide (FIFA, 2014, 2016; UEFA, 2017a).

The remainder of this article is organised as follows: previous literature on the determinants of stadium attendance is reviewed in the following section. The next part presents some background information about the UWCL and highlights important features of women's club football such as the emergence of integrated clubs. The third section provides commentary on the dependent and independent variables and the empirical estimation strategy employed for the analyses. In the fourth section, findings based on regression models are displayed and discussed. The fifth section concludes by suggesting implications that are relevant for women's football clubs and football governing bodies.

\section{Literature review}

\subsection{Determinants of stadium attendance}

The sports economics literature has produced substantive amounts of empirical research on stadium attendance for professional team sports (see Downward, Dawson \& Dejonghe, 2009; Feehan, 2006; and García \& Rodríguez, 2009 for reviews). The usual approach to predict fan interest is the estimation of a demand equation. More precisely, attendance at a sports event is expressed as a function of both socio-economic and sport-related determinants which aid to verify the interest of fans in consuming a particular sport event (e.g. football match).

Socio-economic factors include ticket price, income, population and availability of substitute goods (Downward et al., 2009; Feehan, 2006; García \& Rodríguez, 2009), which are usually controlled in order to determine attributes of each team or geographical area. In women's football, Meier et al. (2016) combined two different measures to control for regional income in Germany and found positive but non-significant results, indicating that women's football matches might represent a normal good. With regards to population size, past studies on sports attendance found that clubs operating in locations with larger populations draw larger 
stadium attendance (Scelles et al., 2013, 2016). However, in women's football, the significance of host site population remains to be confirmed.

Attendance can also vary according to opportunity costs (e.g. distance to the stadium, day of the week) and weather conditions (García \& Rodríguez, 2009). For instance, greater distance between the host cities of the two teams is associated with lower stadium attendance (e.g. potentially higher travel costs for away fans) in women's football (Meier et al., 2016), while increased attendance is displayed for games that are played in the afternoon and for games that are played under favourable weather conditions (e.g. higher temperature and absence of rain) (LeFeuvre et al., 2013; Meier et al., 2016).

Product- or sport-related determinants involve spectators' habit persistence, the expected quality of the match in terms of the characteristics of the teams (e.g. quality of the teams as expected at the start of the season and intra-season, see e.g. Sung \& Mills, 2018), historical or geographical rivalries between clubs (Martins \& Cró, 2018; Wooten, 2018), the significance of the match in a season- or competition-context and the degree of outcome uncertainty. Some of these factors were tested previously in women's football. For example, higher team quality (as reflected in league rankings) produces a positive impact on attendance (LeFeuvre et al., 2013; Meier et al., 2016). Moreover, Meier et al. (2016, p. 15) described women's football as a "niche product targeting mainly dedicated die-hard fans" identifying a positive association between match attendance and supporters' habit persistence (i.e. their past attendance). In addition, Meier et al. (2016) controlled for the quality of the football venue indicating non-significant results, while having previously hosted the FIFA Women's World Cup has been observed to provide a short-term boost to spectator demand (i.e. the season after the competition was held) (LeFeuvre et al., 2013; Meier et al., 2016). Finally, similar to the men's game (e.g. Jewell, 2017; Shapiro, DeSchriver \& Rascher, 2017), spectators positively respond to 'superstar' player effect (LeFeuvre et al., 2013). Yet academic literature has 
provided scarce econometric indications regarding the applicability of outcome uncertainty in women's football. Precisely, only one of the past two studies in women's football controlled for the significance of this factor (Meier et al., 2016).

\subsection{Outcome uncertainty}

Following Szymanski (2003), three types of outcome uncertainty are identified in the sports economics literature: game uncertainty (e.g. individual match outcome), in-season sub competition uncertainty (e.g. championship race, fighting against relegation, competing for a prize) and long-run uncertainty (e.g. domination of a league by a restricted number of teams over a sustained number of seasons). The conceptual propositions on demand for sporting competitions provide that fans tend to prefer more balanced and unpredictable contests. Importantly, the theoretical assumption on competitive balance has played a pivotal role in shaping US professional sports league policies (e.g. salary caps, revenue sharing and reverse order draft), following the principle that the (re)distribution of talent and resources across more teams is essential to keep the competition balanced and maintain the level of fan interest.

Nonetheless, empirical research about the impact of outcome uncertainty on stadium attendance for sport events is far from definitive (Pawlowski, 2013). In fact, scholars who dealt specifically with outcome uncertainty at game-level (frequently measured through the use of betting odds) seldom show evidence to support thoroughly the competitive balance proposition (Pawlowski, 2013). This is the case for both European (Pawlowski, 2013) and American (Jewell, 2017; Sung \& Mills, 2018) men’s football (soccer) leagues. Instead, most studies find that maximum uncertainty does not maximise attendance (Feehan, 2006; Peel \& Thomas, 1992). Rather, it has been observed that it is the ex ante probability of a home team's win which increases stadium attendance. More specifically, examining major league baseball games, Knowles, Sherony and Haupert (1992) argued that demand peaks at the point where a home team's probability of winning is one and a half times higher than that of the visiting team (i.e. 
around 60\%). This finding is also confirmed for men's football (e.g. Forrest \& Simmons, 2002), where additional increases in the home team's probability of winning contribute to lower attendance (i.e. uncertainty and attendance would follow an inverted U-shape).

However, other research finds opposite results, exhibiting a U-shaped relationship between uncertainty and attendance (Peel \& Thomas, 1992). Consistent with this and, as such, contrary to the standard prediction of the uncertainty of outcome hypothesis (UOH), there are studies indicating that supporters show reference-dependent preferences (see e.g. Coates, Humphreys \& Zhou, 2014). These interpretations refer to prospect theory (Kahneman \& Tversky, 1979) and are based on two critical constructs regarding individuals' decision-making under uncertainty: (a) expected losses are treated differently than expected gains; (b) nonexpected utility maximization considerably influences aspects of decisions made under uncertainty. In the case of sports contests, Coates et al. (2014, p. 960) suggested that the existence of the UOH only emerges "when the marginal utility of an unexpected loss exceeds the marginal utility of an unexpected win." In other words, fans' decisions to attend a sport competition is influenced by the opportunity to watch their team either playing a much inferior opponent (i.e. loss aversion) or assuming an outsider role (i.e. upset result). This explanation is also supported when employing a measure of perceived (rather than objective) game uncertainty (Pawlowski, Nalbantis \& Coates, 2018).

In women's football, Meier et al. (2016) adopted two different measures of outcome uncertainty: one for individual match- and one for in-season sub competition-level. Their results show that despite match uncertainty has no significant effect in determining stadium attendance, games involving teams with a chance to win the title attract more fans. However, while Meier et al. (2016)'s study represents the first attempt to control for the effect of uncertainty of outcome over attendance in women's football, the variables used in their article present some limitations. First, the match-level variable is based on the difference in league 
positions between the two competing teams. As acknowledged by the authors, this "represents a rather rough proxy for match uncertainty in comparison to betting odds" (Meier et al., 2016, p. 8). Second, the analysis of in-season sub competition-level uncertainty is restricted to the probability of the two competing teams winning the title, while Scelles et al. (2016) demonstrate that stadium attendance is significantly influenced by the contention of different sporting prizes (or competitive intensity).

To overcome these limitations, in this study, we will introduce betting odds as an objective measure of match outcome uncertainty. As this is the first time that this has been undertaken in women's football, our study will provide new results to the literature. Furthermore, due to the knock-out format of the UWCL, we construct a variable of intra-match uncertainty (Scelles et al., 2011) considering the possibility of score reversal after the first leg game has been played (i.e. competitive intensity, see Method section for more details).

\section{Background}

\subsection{The landscape of the UEFA Women's Champions League}

As part of its strategy to sustain the development of the women's game, UEFA provided the best European women's football clubs with the opportunity to play each other launching the Women's Cup in 2001/02. After its early editions, however, the Women's Cup had generated limited results in terms of appeal and visibility (UEFA, 2008) as the competition was made up of mostly amateur clubs. In an attempt to overcome these initial hurdles, in 2009 UEFA rebranded the competition, changing its name to the UEFA Women's Champions League. Moreover, it started to include more entrants from the top eight nations (the top 12 since 2016) on the basis of the UEFA association coefficient rankings.

Until 2008/09, the Women's Cup included two qualifying rounds, played in the form of mini-tournaments, followed by quarter-finals, semi-finals and finals played on a home-and- 
away basis. Since 2009/10, the UWCL has adopted a format that is more similar to the men's Champions League, including a qualifying group stage and four two-legged knock-out stages (32-stage, 16-stage, quarter-finals and semi-finals) before the final (which is now played in a neutral stadium). In addition to the new format and a revamped brand identity, in 2010 UEFA introduced prize money for the first time, awarding $€ 250,000$ for the winners and $€ 200,000$ for the runners-up. The following year, UEFA extended the payments to semi-finalists and quarterfinalists, aiming to raise the prestige, the competitiveness and the status of UEFA's top competition for women's clubs (UEFA, 2013).

The composition of the UWCL, particularly at the higher competition stages, has been dominated by clubs coming from France and Germany. Also, clubs from England have made their appearances up to the semi-finals more frequently in the last seasons. However, over the nine seasons studied (2009/10-2017/18), the French club Olympique Lyon won the competition five times (including the last three seasons) and was runner-up twice. The other winners were three German clubs, Wolfsburg (winner and runner-up twice), Frankfurt and Turbine Potsdam (winner and runner-up once each). Other runners-up have been the French club Paris SaintGermain (twice) and the Swedish club Tyresö, the only non-French or German club able to reach the final over the period studied.

\subsection{The emergence of integrated women's football clubs}

Concomitant with reforms carried out by UEFA, a gradually increasing number of professional men's football clubs had started to establish a link with and/or integrate a women's team into their management and ownership structures (Aoki et al., 2010; ECA, 2014; Welford, 2013). For example, well-known and historical men's football clubs such as Arsenal, FC Barcelona, Juventus, Olympique Lyon and Wolfsburg have a women's section that plays under the same name and with the same colours as the men's team. 
When men's clubs integrate a women's team, this often becomes part of the same organisation as the men's team, and can therefore benefit from this association in a number of ways (Aoki et al., 2010). Potential advantages deriving from a pre-existent professional men's club structure include the availability of technical and medical expertise, an established sponsorship platform, the possibility to practice in state-of-the-art structures and, most notably, a stronger financial position that can help the women's side secure the best players in the market. However, integration with a men's club can also represent a threat to the women's team financial stability. In fact, integrated women's sides often rely exclusively on the men's club resources and their management can be subject to the strategic decisions of the parent club (Aoki et al., 2010; Welford, 2013). In addition, women's teams that go through this process of integration might risk being perceived as inferior in comparison to the men's team, or as betraying the values connected with the original club and their following communities. For instance, Meier et al. (2016) examined a similar construct by looking at whether a women's club had either seceded from or merged with a men's club. Their findings show that integration with an established men's football club leads to diminished stadium attendance for the women's side, indicating that integration was not well received by fans of clubs competing in the Women's Bundesliga.

Nevertheless, we argue that integration can be an opportunity to generate visibility and additional fan interest for both the integrated women's club and women's football as a whole. Examples of positive associations between clubs with an integrated ownership and increased attention come from different parts of the world. For instance, the Spanish La Liga recently launched a new women's league which constituted primarily of teams that are integrated with a men's club, which has led to the first official sponsorship contract for the league (LaLiga, 2016). Similarly, the entrance of Juventus in the Italian women's top division resulted in increased visibility and interest from other men's clubs in investing in a women's side 
(Castellano, 2018). The integrated ownership model has helped attract high numbers of spectators also in Central and South American nations. For example, in Mexico, each of the two La Liga MX Femenil's final games between Pachuca and Chivas de Guadalajara were played in front of a crowd of around 30,000 spectators (AS Mexico, 2018). Therefore, it might be assumed that these clubs' recognisable brand and reputation can help the whole sport increase its visibility. Related to this, past studies have suggested that attendance at men's football matches may be driven by the brand following of the visiting club (Coates, Naidenova \& Parshakov, 2017; Czarnitzki \& Stadtmann, 2002; Pawlowski \& Anders, 2012). Thus, we suggest that the presence of a women's integrated club, where men's side has a prominent reputation, will be positively reflected in the number of spectators at the stadium. We build upon past findings to verify the impact of such 'superclub' effect at the individual game-level in women's football.

\section{Method}

\subsection{Dataset and variables}

All matches played in the UWCL qualifying rounds (group stage) and knockout phases (32-stage to semi-finals) between 2009/10 and 2017/18 formed the basis of the empirical analysis. The final was omitted for each season due to these games taking place in neutral stadiums. The period from $2009 / 10$ to $2017 / 18$ was selected due to unavailability of variables such as betting odds or stadium attendance data for previous seasons. The final sample consists of 554 games. Table 1 provides an overview of the measures used in this study.

To account for trends in attendance we employed a set of distinct dummies for each season. Similarly, stage of the competition was controlled by dummy variables. With regards to this factor, attendance would be expected to increase as the competition reaches its final stages due to the potentially better quality that is displayed in these games. 
Both home and away teams' recent performances are found as positive determinants of stadium attendance (Pawlowski \& Anders, 2012). To capture this effect in our model, we calculated the number of points scored by the home and the away teams in the five national league matches played prior to the UWCL game.

The urban area population of the home team site was considered to determine each club's potential market size. Further, we included data about income per capita for the location where each team is based using data that are clustered on the smallest unit of administration of Nomenclature Territorial Units for Statistics (NUTS3) (Eurostat, 2018). ${ }^{1}$ This gives us the possibility to measure economic information depending on each club's location, although it is important to consider that it was not possible to retrieve game-level price data, which limits the understanding of the specific price effect on attendance. Nonetheless, most women's teams operate either a free-of-charge entrance policy or charge fans a very modest sum to attend matches. ${ }^{2}$ For instance, ticket prices for the last two UWCL finals equalled $€ 7$ in 2016/17 and $€ 3.20$ in 2017/18 (UEFA, 2017b, 2018).

We measured distance between home and away teams' host cities to control for potential travelling costs for away supporters (although it is not possible to distinguish between home and away fans). Furthermore, we included a dummy variable indicating whether clubs are based in the same country. Previous studies in men's football controlled for 'derby' or 'rivalries' in national competitions, while our paper analyses a multinational tournament. This allows us to verify whether matches where the two competing teams come from the same

\footnotetext{
${ }^{1}$ NUTS is a geocode standard for referencing the subdivisions of countries for statistical purposes in European Union member states. The classification of regions is divided into three levels: major (NUTS 1), basic (NUTS 2) and small (NUTS 3). Note that we used country's GDP per capita for clubs that are based in non-EU countries.

${ }^{2}$ Examples from some of the most successful women's football clubs are presented here: Arsenal Women - the most successful English women's football club by number of trophies - and Manchester City Women - English 2016 Women Super League winner and 2017/18 UWCL semi-finalist - charge adults $£ 6$ for all their home games (Arsenal, 2018; Manchester City, 2018); Olympique Lyon - five-times UWCL winner - charged $€ 5$ for the UWCL 16-stage return leg in 2017/18 (Olympique Lyon, 2017).
} 
country attract larger audiences than other UWCL games (e.g. potential derby). Controls for opportunity costs related to the scheduling of the game (i.e. week-day/end) and weather conditions (i.e. temperature and rain) were inputted in our demand equation.

Following Peel and Thomas (1992), and Pawlowski and Anders (2012), betting odds for the probabilities of home team's win, away team's win and draw game served to operationalise match outcome uncertainty. These three conditions were condensed via the calculation of the Theil measure for uncertainty (see Theil, 1967):

$$
T H E I L=\sum_{i=1}^{3} \frac{p_{i}}{\sum_{i=1}^{3} p_{i}} \log \left(\frac{\sum_{i=1}^{3} p_{i}}{p_{i}}\right)
$$

where $p_{i}$ reports the home team's win probability, the away team's win probability, as well as the draw probability of a certain match based on unbiased betting odds provided by oddsportal.com. The Theil index increases when the ex ante uncertainty of match outcome is higher and vice versa. Related to this, the probability of home team's win and its squared term were used in an alternative model to verify the existence of reference-dependent preferences. ${ }^{3}$

In addition to a standard measure of individual game outcome uncertainty, this study controls for competitive intensity (Scelles et al., 2013, 2016). In the UWCL knock-out stages, teams play each other twice on a home-and-away basis (i.e. once at each team's home ground). The final result of each match is determined by the aggregate score of the two individual fixtures. When aggregate scores are equal, the 'away goal rule' is applied (i.e. any goals scored away count double when aggregate scores are equal). Football being a low-scoring sport, a lower goal difference (including the 'away goal rule') before the second leg is played would

\footnotetext{
${ }^{3}$ The Theil index as well as the probability of home team's win and its squared term were also used simultaneously in another model (see Results and discussion section).
} 
be expected to determine higher interest from fans due to the final score still being in contention (i.e. competitive intensity).

Based on what is described in Section 3.2, a variable controlling for the possibility that integrated clubs have an effect on attendance was included in the estimation equation. The presence of clubs with an integrated model of ownership is now common across many European countries (ECA, 2014). However, it is reasonable to argue that those integrated clubs that are based in the most financially lucrative (and therefore more renowned) men's leagues (e.g. England, France, Germany, Italy and France, referred as 'the Big-five') are more likely to produce a significant 'superclub' effect. To provide a practical example, despite both men's clubs having a women's side, the brand of FC Barcelona (Spain) is internationally more popular than the one of Stabæk (Norway). Hence, an additional dummy variable was formulated indicating whether teams were integrated and based in one of the Big-five leagues ${ }^{4}$.

Table 2 presents the summary statistics for the dependent and independent variables.

\subsection{Estimation strategy}

The estimation strategy for this study is a demand equation that distinguishes among groups of explanatory factors that have an effect on attendance. The standard model to be estimated is:

\footnotetext{
${ }^{4} \mathrm{~A}$ variable controlling for integrated clubs that are not based in the Big-five and one controlling for home team supporters' habit persistence were also tested. These provided non-significant results and are therefore not displayed in the paper. Results are available upon request.
} 


$$
\begin{aligned}
& \operatorname{Ln}\left(\text { Att }_{\text {gijt }}\right)=\beta_{0}+\beta_{1} \text { Recent Performance }_{i}+\beta_{2} \text { Recent Performance }_{j} \\
& +\beta_{3} \operatorname{Ln}\left(\text { Population }_{i}\right)+\beta_{4} \operatorname{Ln}\left(\text { Income }_{i t}\right)+\beta_{5} \operatorname{Ln}\left(\text { Income }_{j t}\right) \\
& +\beta_{6} \operatorname{Ln}(\text { Distance })+\beta_{7} \text { Same country }+\beta_{8} \text { Weekend }+\beta_{9} \text { Temperature } \\
& +\beta_{10} \text { Rain }+\beta_{11} \text { Theil }+\beta_{12} \text { Win Probability } \\
& +\beta_{13} \text { Competitive Intensity } \\
& +\beta_{14} \text { Ownership }_{i}+\beta_{15} \text { Ownership }_{j}+\beta_{16} \text { Big Five }_{i}+\beta_{17} \text { Big Five }_{j} \\
& +\beta_{18} \text { Ownership }_{i} * \text { Big Five }_{i}+\beta_{19} \text { Ownership }_{j} * \text { Big Five }_{j} \\
& +\tau_{t}+\varphi_{g}+\mu_{i}+\varepsilon_{g i j t}
\end{aligned}
$$

where the dependent variable is the log-attendance for the match $g$ between home team $i$ and away team $j$ in season $t$. The yearly effects are represented by $\tau$ while $\varphi$ is the dummy for the tournament stage. To control for unobserved heterogeneity across home teams' countries, we input $\mu$. Our empirical specifications include alternative models to test the significance of various determinants of stadium attendance (e.g. with and without uncertainty of outcome and home team's win probability). The specification above implies random effects (RE) for home and away teams due to lack of variability across our short time periods for variables such as income and population. Further, we control for club-specific unobserved heterogeneity in a model that accounts for individual home teams' fixed-effect (FE). This allows the models to focus on uncertainty variables. Breusch-Pagan test revealed heteroscedasticity in our data $(\mathrm{p}<$ .05). Therefore, robust standard errors were applied. The software used for the analysis was Stata/IC 14.2.

\section{Results and discussion}

The empirical results of this study (reported in Table 3 and Table 4) offer insights into the effect of contextual- and sport-related determinants of stadium attendance in women's 
football. Both our FE and RE models predict a moderate percentage of within-clubs variation $\left(R^{2}=45 \%\right)$, while, as expected, the RE specification performs better in explaining variance in stadium attendance between the teams $\left(72 \%<R^{2}<73 \%\right)$ than the FE models $\left(R^{2}=17 \%\right)$.

As graphically presented in Figure 1, attendance reached peaks of interest in 2015/16 and 2016/17. Alongside attendance for games played in 2011/12, seasonal dummies are consistently positive and some of these present significant results across all models. However, if we compare the first and the last years of our dataset, attendance has remained relatively stable over time. Also, stadium attendance figures remain very low if compared to average crowd sizes for top quality men's football. This means that despite the fact that the women's game has experienced increasing levels of attention by football governing bodies in recent years (FIFA, 2014, 2016; UEFA, 2017a), these efforts have not yet resulted in increased numbers of spectators. In line with previous studies, this provides little support for the idea that fan interest in women's football is developing constantly and continuously (Allison, 2016; Meier et al., 2016; Southall et al., 2005).

As expected, a positive and significant effect is reported for games played in the knockout stages compared to matches played in the qualifying group stage. Coefficients for quarterfinals and semi-finals denote a greater impact on attendance for stages that are closer to the final. Both home and away teams' recent performances were controlled via the percentage of points won in the five national league games preceding the UWCL match. These variables indicate non-significant results, meaning that fans are not specifically interested in successful teams.

With regards to the effect of contextual variables, population is omitted in FE models due to the inclusion of home club-specific effect while it is non-significant in RE specifications. Likewise, income has a non-significant impact on attendance. Yet the different signs in the 
coefficient between FE and RE specifications would suggest that an increase in income for a given club's area generates an increase in fan attendance (FE). However, clubs in areas with lower income attract more fans than clubs in areas with higher income (RE).

In line with Meier et al. (2016), the negative sign of distance indicates that fans might be unwilling to follow their team when away matches are located in a distant place. However, this has a non-significant impact in our results. As shown by the positive sign of the variable Same country, matches where the two competing clubs come from the same nation have the potential to attract larger audiences. Nonetheless, the effect is non-significant across all models. The effect of temperature is significantly positive on attendance, while rain and scheduling variables yield non-significant results.

Looking at the sport-specific factors, the Theil index measuring uncertainty of match outcome displays a positive coefficient and a significant effect. This means that (a priori) match outcome uncertainty favours stadium attendance increases. In addition, alternative model specifications present a significant effect of home team's win probability on attendance. This resembles an inverted-U shape with coefficients of home team's win probability and its squared term showing that fan interest peaks when the probability for the home team to win is 0.41 (RE) and 0.43 (FE). This fairly low probability may indicate that uncertainty of match outcome matters more than a higher home team's win probability. ${ }^{5}$ Models (reported in Table 4) including both uncertainty of match outcome and home team team's win probability show that uncertainty of match outcome has a non-significant positive impact, while the association between attendance and home team win's probability now follows a U shape and becomes nonsignificant. These findings do not provide support to the hypothesis indicating that spectators show either loss aversion or interest in one-sided games (e.g. Coates et al., 2014). In contrast,

\footnotetext{
${ }^{5}$ Although it should be kept in mind that draws are possible in football (average adjusted probability equal to $16.8 \%$ for draws vs. $48.4 \%$ for home wins and $34.8 \%$ for away wins in our dataset).
} 
women's football supporters seem to give up on attending games where there is a clear favourite, suggesting that they might evaluate the possibility of a surprising result (i.e. utility maximisation) as being very unlikely to happen. This is further supported by the negative sign of competitive intensity. In fact, the negative sign for competitive intensity indicates that fans are reluctant to attend second-leg games if the difference in aggregate score is already high after the first-leg match has been played. In other words, women's football fans are not interested in games where there is a clear favourite.

Lastly, when the away team belongs to the 'superclub' category, we find significant positive effects on stadium attendance. Similar to men's football (Coates et al., 2017; Czarnitzki \& Stadtmann, 2002; Pawlowski \& Anders, 2012), this means that spectators' decision to attend a match in person is influenced by the brand strength of the away team. Importantly, clubs with an integrated structure that are based in one of the Big-five leagues have the greatest impact on demand in women's football.

\subsection{Managerial implications}

Findings presented here help expand the debate on the positioning of women's football overall and provide women's football stakeholders with guidance in respect of stadium attendance. First, given the slow pace of growth in attendance for the top European club competition in recent years, the progression of women's football towards financial sustainability seems problematic in the short-term. Second, UWCL attendance responds to a 'superclub' effect as demonstrated by the positive impact of the variable integrated and Big-5 away team (32 to $40 \%$ more fans than independent non Big-5 away team). Specifically, it appears that brand strength can be 'transferrable' from the men's to the women's section as supporters might associate the brand of a men's club with its integrated women's side. Hence, professional men's clubs with a recognisable brand should be encouraged to invest in a 
women's section to increase the visibility of the sport. However, at the same time, the positioning of those pioneering all-female independent clubs needs protection, as they may be put at risk due to the financial power of integrated clubs. Therefore, before directing any specific policy actions in this area, it is important to consider more broadly whether the aim of women's football should be to end up at the same or a different place as the men's game in terms of its commercialisation (Morrow, 2017).

Third, moving to outcome uncertainty and competitive intensity, the significant associations identified between these two variables and attendance is of particular importance for football governing bodies and clubs, as they consider potential changes in the competition format (ECA, 2018). ${ }^{6}$ However, maintaining (or improving) the level of match uncertainty is complex. In the case of women's football, it is reasonable to suggest that the relatively low interest of spectators in attending the stadium might be due to the transitioning period of women's football in terms of its popularity and the still relatively low participation rates in many countries. For instance, it is possible that due to the low numbers of participants, only a few players per team are currently able to produce outstanding performances. That said, football governing bodies need to continue their efforts in strengthening the rate of participation at grassroots levels. In fact, over time, this is expected to narrow the gap between players' performances and therefore encourage contests that are more balanced (for a discussion on the relationship between available playing talent and changes in competitive balance, see Berri et al., 2005; Flores, Forrest \& Tena, 2010; Schmidt \& Berri, 2003). An additional direction relates to the need to further improve both distributions (i.e. number of clubs awarded) and overall levels of prize money. Importantly, Frick (2011) explored differences in prize money between men's and women's professional distance running and empirically demonstrated that

\footnotetext{
${ }^{6}$ More precisely, our results indicate that for every additional goal separating home and away teams after the firstleg (i.e. lower competitive intensity), stadium attendance for the second-leg game decreases of $2 \%$. The marginal effect of uncertainty of outcome is more difficult to interpret due to the nature of the Theil measure.
} 
competitive balance of the women's sport improved in line with increasing returns to success (i.e. higher prize money).

\subsection{Conclusions and future research}

This study of fan interest presents an original contribution with regards to stadium attendance in women's football and offers interesting perspectives about the development of the women's game in Europe. Our results highlight the importance of outcome uncertainty as a critical determinant of stadium attendance for elite women's football. Also, this study indicates that supporters of women's football are not driven by the quality of the competing teams. In contrast, they seem to be motivated to watch clubs with a brand that is recognisable from the men's game. In this direction, there is a potential for spillover effects between men's and women's sections of football clubs with an integrated structure. Thus, this scenario requires further investigation. For instance, future research could focus on club-specific characteristics to determine what factors (e.g. club's history of success) motivate fans to attend the stadium. Also, opportunities for cross-fertilisation between supporters of men's and women's football should be examined more closely. In addition, future studies should continue to investigate fan culture in relation to women's football teams (e.g. Guest \& Lujten, 2017), as this can provide a better understanding of how supporters can be attracted and retained in women's football. Furthermore, the availability of substitute products and the opportunity to watch the game on TV should be considered in future studies of attendance demand in order to provide more precise interpretations regarding the behaviour of women's football fans. 


\section{Acknowledgements}

We would like to thank the editor and two anonymous referees for helpful and constructive comments.

\section{Funding sources}

This research did not receive any specific grant from funding agencies in the public, commercial, or not-for-profit sectors. 


\section{References}

Allison, R. (2016). Business or cause? Gendered institutional logics in women's professional soccer. Journal of Sport and Social Issues, 40(3), 237-262.

Andreff, W., \& Scelles, N. (2015). Walter C. Neale 50 years after: Beyond competitive balance, the league standing effect tested with French football data. Journal of Sports Economics, 16(8), 819-834.

Aoki, K., Crumbach, S., Naicker, C., Schmitter, S., \& Smith, N. (2010). Identifying best practice in women's football: Case study in the European context. FIFA Master $10^{\text {th }}$ Edition, unpublished thesis, available at: http://www.ciesuni.org/sites/default/files/identifying_best_practices_in_women_football.pdf (accessed 18 August 2016).

Arsenal (2018). Arsenal Women tickets, available at: https://arsenal.com/tickets/womentickets (accessed 13 June 2018).

AS Mexico (2018). Pachuca vence a Chivas en la ida de la final de Liga MX Femenil, available at: $\quad$ https://mexico.as.com/mexico/2017/11/21/futbol/1511240222_977866.html (accessed 13 June 2018).

Berri, D. J., Brook, S. L., Frick, B., Fenn, A. J, \& Vicente-Mayoral, R. (2005). The short supply of tall people: Competitive imbalance and the National Basketball Association. Journal of Economic Issues, 39(4), 1029-1041.

Castellano, L. (2018). Martina Rosucci: «La Juve sta dando grande visibilità al movimento femminile», available at: https://juventusnews24.com/martina-rosucci-juve-grandevisibilita-movimento-femminile/ (accessed 13 June 2018).

Coates, D., Naidenova, I., \& Parshakov, P. (2017). Determinants of Russian football club brands. International Journal of Sport Finance, 12(4), 321-341. 
Coates, D., Humphreys, B. R., \& Zhou, L. (2014). Reference-dependent preferences, loss aversion, and live game attendance. Economic Inquiry, 52(3), 959-973.

Cooky, C., Messner, M. A., \& Hextrum, R. H. (2013). Women play sport, but not on TV: A longitudinal study of televised news media. Communication \& Sport, 1(3), 203-230.

Czarnitzki, D., \& Stadtmann, G. (2002). Uncertainty of outcome versus reputation: Empirical evidence for the First German Football Division. Empirical Economics, 27, 101-112.

Downward, P., Dawson, A., \& Dejonghe, T. (2009). The demand for professional team sports: Attendance and broadcasting. In Downward, P., Dawson, A., \& Dejonghe, T. (Eds.) Sports Economics: Theory, Evidence and Policy, Butterworth-Heinemann: Oxford, pp. 261-300.

ECA (2014). European Clubs' Association - Women's Football Committee - Women's Club Football Analysis (Report), available at http://www.ecaeurope.com/PageFiles/7585/ECA_Womens\%20Club\%20Football\%20 Analysis_double\%20pages.pdf (accessed 22 November 2016).

ECA (2018). European Club Association - Media Release: The ECA Executive Board, available at: https://www.ecaeurope.com/news/eca-executive-board-meets-in-warsaw/ (accessed 9 July 2018).

Eurostat (2018). Gross domestic product (GDP) at current market prices by NUTS 3 regions, available at: http://appsso.eurostat.ec.europa.eu/nui/show.do?dataset=nama_10r_3gdp\&lang=en (accessed 8 January 2019).

Feehan, P. (2006). Attendance at sports events. In Andreff, W. \& Szymanski, S. (Eds.) Handbook on the Economics of Sport, Edward Elgar: Cheltenham, pp. 90-99. 
FIFA

$$
\text { (2014). }
$$

The

women`s

survey,

available

at:

http://www.fifa.com/mm/document/footballdevelopment/women/02/52/26/49/women sfootballsurvey2014_e_english.pdf (accessed 7 October 2016).

FIFA (2016). FIFA 2.0: The vision for the future, available at: https://www.sportanddev.org/sites/default/files/downloads/fifa_2.0. the vision_for_t he future.pdf (accessed 22 November 2016).

FIFPro (2017). 2017 FIFPro global employment report: Working conditions in professional women's football, available at: https://www.fifpro.org/attachments/article/6986/2017\%20FIFPro\%20Women\%20Foo tball\%20Global\%20Employment\%20Report-Final.pdf (accessed 15 December 2017).

Flores, R., Forrest, D., \& Tena, D. (2010). Impact on competitive balance from allowing foreign players in a sports league: Evidence from European soccer. Kyklos, 63(4), 546557.

Forrest, D., \& Simmons, R. (2002). Outcome uncertainty and attendance demand in sport: The case of English soccer. Statistician, 51(2), 229-241.

Frick, B. (2011). Gender differences in competitiveness: Empirical evidence from professional distance running. Labour Economics, 18(3), 389-398.

Funk, D. C., Ridinger, L. L. \& Moorman, A. M. (2003). Understanding consumer support: Extending the Sport Interest Inventory (SII) to examine individual differences among women's professional sport consumers. Sport Management Review, 6(1), 1-31.

García, J., \& Rodríguez, P. (2009). Sports attendance: A survey of the literature 1973-2007. Rivista di Diritto ed Economia dello Sport, 5(2), 111-151.

Guest, A. M., \& Luijten, A. (2017). Fan culture and motivation in the context of successful women's professional team sports: A mixed-methods case study of Portland Thorns fandom. Sport in Society, 21(7), 1013-1030. 
Hallmann, K. (2012). Women's 2011 football World Cup: The impact of perceived images of women's soccer and the World Cup 2011 on interest in attending matches. Sport Management Review, 15(1), 33-42.

Jewell, R.T. (2017). The effect of marquee players on sports demand: The case of US Major League Soccer. Journal of Sports Economics, 18(3), 239-252.

Kahneman, D., \& Tverski, A. (1979). Prospect theory: An Analysis of decision under risk. Econometrica, 47(2), 263-292.

Knowles, G., Sherony, K., \& Haupert, M. (1992). The demand for Major League Baseball: A test of the uncertainty of outcome hypothesis. The American Economist, 36(2), 72-80.

LaLiga (2016). Iberdrola to sponsor the women's First Division, available at: http://laliga.es/en/news/iberdrola-to-sponsor-the-womens-first-division (accessed 13 June 2018).

LeFeuvre, A. D., Stephenson, F. E., \& Walcott, S. M. (2013). Football frenzy: The effect of the 2011 World Cup on Women's Professional Soccer League attendance. Journal of Sports Economics, 14(4), 440-448.

Manchester City (2018). Match tickets, available at: http://manchestercity.fawsl.com/tickets.html (accessed 13 June 2018).

Martins, A. M., \& Cró, S. (2018). The demand for football in Portugal: New insights on outcome uncertainty. Journal of Sports Economics, 19(4), 473-497.

Meier, H. E., Konjer, M., \& Leinwather, M. (2016). The demand for women`s league soccer in Germany. European Sport Management Quarterly, 16(1), 1-19.

Morrow, S. (2017). Football, economics and finance. In Hughson, J., Moore, K., Spaaij, R., Maguire, J., Routledge Handbook of Football Studies, Routledge, New York, pp. 163176. 
Olympique Lyon (2017). UWCL ticketing: OL Women - Medyk Konin, available at: https://olweb.fr/en/article/uwcl-ticketing-ol-women-medyk-konin-32091.html (accessed 13 June 2018).

Pawlowski, T. (2013). Testing the uncertainty of outcome hypothesis in European professional football: A stated preference approach. Journal of Sports Economics, 14(4), 341-367.

Pawlowski, T., \& Anders, C. (2012). Stadium attendance in German professional football: The (un)importance of uncertainty of outcome reconsidered. Applied Economics Letters, 19(16), 1553-1556.

Pawlowski, T., Nalbantis, G., \& Coates, D. (2018). Perceived game uncertainty, suspense and the demand for sport. Economic Inquiry, 56(1), 173-192.

Peel, D. A., \& Thomas, D. A. (1992). The demand for football: Some evidence on outcome uncertainty. Empirical Economics, 17(2), 323-331.

Pfister, G. (2015). Assessing the sociology of sport: On women and football. International Review for the Sociology of Sport, 50(4-5), pp. 563-569.

Scelles, N., Durand, C., Bah S. T., \& Rioult, F. (2011). Intra-match competitive intensity in French football Ligue 1 and rugby Top 14. International Journal of Sport Management and Marketing, 9(3/4), 154-169.

Scelles, N., Durand, C., Bonnal, L., Goyeau, D., \& Andreff, W. (2013). Competitive balance versus competitive intensity before a match: Is one of these two concepts more relevant in explaining attendance? The case of the French football Ligue 1 over the period 20082011. Applied Economics, 45(29), 4184-4192.

Scelles, N., Durand, C., Bonnal, L., Goyeau, D., \& Andreff, W. (2016). Do all sporting prizes have a significant positive impact on attendance in a European national football league? Competitive intensity in the French Ligue 1. Economic Policy, 11(3), 82-107. 
Schmidt, M. B., \& Berri, D. J. (2003). On the evolution of competitive balance: The impact of an increasing global search. Economic Inquiry, 41(4), 692-704.

Shapiro, S.L., DeSchriver, T.D., \& Rascher, D.A. (2017). The Beckham effect: Examining the longitudinal impact of a star performer on league marketing, novelty, and scarcity. European Sport Management Quarterly, 17, 610-634.

Southall, R. M., Nagel, M. S. \& LeGrande, D. J. (2005). Build it and they will come? The Women's United Soccer Association: A collision of exchange theory and strategic philanthropy. Sport Marketing Quarterly, 14(3), 158-167.

Sung, H., \& Mills, B. M. (2018). Estimation of game-level attendance in major league soccer: Outcome uncertainty and absolute quality considerations. Sport Management Review, 21(5), 519-532.

Szymanski, S. (2003). The economic design of sporting contests. Journal of Economic Literature, 41(4), 1137-1187.

Theil, H. (1967). Economics and information theory (Vol. 7). Amsterdam: North Holland.

UEFA (2008). Women's Champions League launches in 2009, available at: https://uefa.com/womenschampionsleague/news/newsid=781313.html (accessed 9 July 2018).

UEFA (2013). UEFA Women's Champions League, available at: https://www.uefa.com/MultimediaFiles/Download/EuroExperience/competitions/Gen eral/01/72/39/64/1723964_DOWNLOAD.pdf (accessed 9 July 2018).

UEFA (2017a). Women's Football across the National Associations 2017, available at: https://www.uefa.com/MultimediaFiles/Download/OfficialDocument/uefaorg/Women 'sfootball/02/51/60/57/2516057_DOWNLOAD.pdf (accessed 20 December 2017). 
UEFA (2017b). Women's Champions League final tickets on sale, available at: https://uefa.com/womenschampionsleague/news/newsid=2441643.html (accessed 13 June 2018).

UEFA (2018). Women's Champions League final tickets sales, available at: https://uefa.com/womenschampionsleague/ticketing/index.html (accessed 13 June 2018).

Welford, J. (2013). Outsiders on the inside: Integrating female and male football clubs in the UK, paper presented at Football Research in an Enlarged Europe (FREE) conference, June, University of Copenhagen (Denmark).

Wooten, J.J. (2018). A case for complements? Location and attendance in Major League Soccer. Applied Economics Letters, 25(7), 442-446. 
Table 1. Description of variables.

\begin{tabular}{|c|c|c|c|}
\hline Variable & Description & Measure & Source \\
\hline Attendance & $\begin{array}{c}\text { Number of spectators at the } \\
\text { game }\end{array}$ & Ln (attendance) & $\begin{array}{c}\text { worldfootball.net; } \\
\text { women.soccerway.com }\end{array}$ \\
\hline Season & $\begin{array}{c}\text { Season in which the game was } \\
\text { played }\end{array}$ & $\begin{array}{l}\text { Seasonal dummies } \\
(2009 / 10-2017 / 18)\end{array}$ & \\
\hline $\begin{array}{r}\text { Stage of } \\
\text { competition }\end{array}$ & $\begin{array}{l}\text { Stage of the competition in } \\
\text { which the game was played }\end{array}$ & $\begin{array}{l}\text { Dummy variable for each } \\
\text { stage (group stage to semi- } \\
\text { final) }\end{array}$ & \\
\hline $\begin{array}{r}\text { Recent } \\
\text { performance } \\
\text { home team }\end{array}$ & $\begin{array}{l}\text { Points won by the home team } \\
\text { as a percentage of the possible } \\
\text { points in the previous } n \text { (max. = } \\
\text { 5) matches in season } t \text { (national } \\
\text { league games only) }\end{array}$ & $\begin{array}{l}\text { Points won / points } \\
\text { available }\end{array}$ & $\begin{array}{l}\text { Clubs' official website; } \\
\text { women.soccerway.com }\end{array}$ \\
\hline $\begin{array}{r}\text { Recent } \\
\text { performance } \\
\text { away team }\end{array}$ & $\begin{array}{l}\text { Points won by the away team as } \\
\text { a percentage of the possible } \\
\text { points in the previous } n \text { (max. = } \\
\text { 5) matches in season } t \text { (national } \\
\text { league games only) }\end{array}$ & & \\
\hline Population & Population of the host city & Ln (population) & citypopulation.de \\
\hline $\begin{array}{r}\text { Income home } \\
\text { team }\end{array}$ & $\begin{array}{l}\text { Income per capita in the } \\
\text { corresponding NUTS } 3 \text { region } \\
\text { for the home team }\end{array}$ & Ln (income) & Eurostat (ec.europa.eu) \\
\hline $\begin{array}{r}\text { Income away } \\
\text { team }\end{array}$ & $\begin{array}{l}\text { Income per capita in the } \\
\text { corresponding NUTS } 3 \text { region } \\
\text { for the away team }\end{array}$ & & \\
\hline Distance & $\begin{array}{c}\text { Distance between home and } \\
\text { away teams }\end{array}$ & Distance in $\mathrm{km}$ & distancefromto.net \\
\hline \multirow[t]{2}{*}{ Same country } & $\begin{array}{l}\text { Dummy variable used to } \\
\text { capture matches in which teams } \\
\text { come from the same country }\end{array}$ & $\begin{array}{c}\text { Dummy: } 1=\text { clubs are from } \\
\text { the same country; }\end{array}$ & \\
\hline & & $\begin{array}{c}0=\text { clubs are from different } \\
\text { countries }\end{array}$ & \\
\hline Weekend & $\begin{array}{c}\text { Whether the match is played on } \\
\text { a weekday/end }\end{array}$ & $\begin{array}{l}\text { Dummy: } 1=\text { weekend; } \\
\text { 0 = weekday }\end{array}$ & \\
\hline \multirow[t]{2}{*}{ Temperature } & $\begin{array}{l}\text { Temperature in the host city on } \\
\text { match day }\end{array}$ & Temperature in ${ }^{\circ} \mathrm{C}$ & timeanddate.com \\
\hline & $\begin{array}{l}\text { Rain in the host city on match } \\
\text { day }\end{array}$ & $\begin{array}{l}\text { Dummy: } 1=\text { rain } \\
0=\text { no rain }\end{array}$ & timeanddate.com \\
\hline $\begin{array}{r}\text { Uncertainty of } \\
\text { outcome }\end{array}$ & $\begin{array}{l}\text { The level of uncertainty of } \\
\text { outcome for the match played } \\
\text { based on betting odds }\end{array}$ & Theil measure & oddsportal.com \\
\hline
\end{tabular}




\begin{tabular}{|c|c|c|c|}
\hline Variable & Description & Measure & Source \\
\hline $\begin{array}{r}\text { Win } \\
\text { probability } \\
\text { home team }\end{array}$ & $\begin{array}{l}\text { Predicted home team's } \\
\text { probability to win based on } \\
\text { betting odds }\end{array}$ & $\begin{array}{c}\text { Adjusted home team's } \\
\text { probability to win in } \\
\text { percentage based on betting } \\
\text { odds }\end{array}$ & oddsportal.com \\
\hline $\begin{array}{r}\text { Competitive } \\
\text { intensity }\end{array}$ & $\begin{array}{l}\text { The possibility of score } \\
\text { reversals after the first leg } \\
\text { game }\end{array}$ & $\begin{array}{l}\text { Exact goal difference in } \\
\text { absolute value after the first } \\
\text { leg (including away goal } \\
\text { rule) for the second leg } \\
\text { games; } 0=\text { otherwise }\end{array}$ & \\
\hline $\begin{array}{l}\text { Ownership } \\
\text { home team }\end{array}$ & Home team's type of ownership & $\begin{array}{c}\text { Dummy: } 1=\text { integrated; } \\
0=\text { independent }\end{array}$ & Clubs' official website \\
\hline $\begin{array}{l}\text { Ownership } \\
\text { away team }\end{array}$ & Away team's type of ownership & & \\
\hline $\begin{array}{r}\text { Big-5 home } \\
\text { team }\end{array}$ & $\begin{array}{c}\text { Dummy variable used to } \\
\text { capture whether the home team } \\
\text { is based in one of the Big-5 } \\
\text { leagues }\end{array}$ & $\begin{array}{l}\text { Dummy: } 1 \text { = Big-5; } \\
\text { 0 = Non Big-5 }\end{array}$ & \\
\hline $\begin{array}{r}\text { Big-5 away } \\
\text { team }\end{array}$ & $\begin{array}{c}\text { Dummy variable used to } \\
\text { capture whether the away team } \\
\text { is based in one of the Big-5 } \\
\text { leagues }\end{array}$ & & \\
\hline $\begin{array}{r}\text { Integrated and } \\
\text { Big-5 home } \\
\text { team }\end{array}$ & $\begin{array}{c}\text { Matches where the home team } \\
\text { is an integrated club from the } \\
\text { Big-5 leagues (e.g. 'superclub' } \\
\text { effect) }\end{array}$ & $\begin{array}{l}\text { Dummy: } 1=\text { integrated and } \\
\text { Big- } 5 ; \\
0=\text { all clubs (integrated and } \\
\text { independent) not from Big- }\end{array}$ & \\
\hline $\begin{array}{r}\text { Integrated and } \\
\text { Big-5 away } \\
\text { team }\end{array}$ & $\begin{array}{l}\text { Matches where the away team } \\
\text { is an integrated clubs from the } \\
\text { Big-5 leagues (e.g. 'superclub' } \\
\text { effect) }\end{array}$ & 5 & \\
\hline
\end{tabular}


Table 2. Descriptive statistics of dependent and independent variables.

\begin{tabular}{|c|c|c|c|c|}
\hline Variable & Mean & Std. deviation & Min & Max \\
\hline Attendance & 6.88 & 1.15 & 3.43 & 10 \\
\hline Habit persistence home team & 6.38 & 0.98 & 4.50 & 8.04 \\
\hline Recent performance home team & 0.83 & 0.19 & 0 & 1 \\
\hline Recent performance away team & 0.83 & 0.17 & 0.13 & 1 \\
\hline Population & 12.57 & 1.54 & 7.77 & 16.09 \\
\hline Income home team & 10.03 & 1.11 & 7.04 & 12.26 \\
\hline Income away team & 10.06 & 1.15 & 6.26 & 12.26 \\
\hline Distance & 7.01 & 0.72 & 4.57 & 8.63 \\
\hline Same country & 0.02 & 0.16 & 0 & 1 \\
\hline Weekend & 0.15 & 0.35 & 0 & 1 \\
\hline Temperature & 14.59 & 8.26 & -12 & 37 \\
\hline Rain & 0.14 & 0.35 & 0 & 1 \\
\hline Uncertainty of outcome & 0.75 & 0.24 & 0.28 & 1.09 \\
\hline Competitive intensity & 1.04 & 1.86 & 0 & 14 \\
\hline Win probability home team & 0.48 & 0.30 & 0.02 & 0.93 \\
\hline Ownership home team & 0.52 & 0.49 & 0 & 1 \\
\hline Ownership away team & 0.46 & 0.49 & 0 & 1 \\
\hline Big-5 home team & 0.35 & 0.47 & 0 & 1 \\
\hline Big-5 away team & 0.35 & 0.47 & 0 & 1 \\
\hline Integrated and Big-5 home team & 0.23 & 0.42 & 0 & 1 \\
\hline Integrated and Big-5 away team & 0.23 & 0.42 & 0 & 1 \\
\hline
\end{tabular}




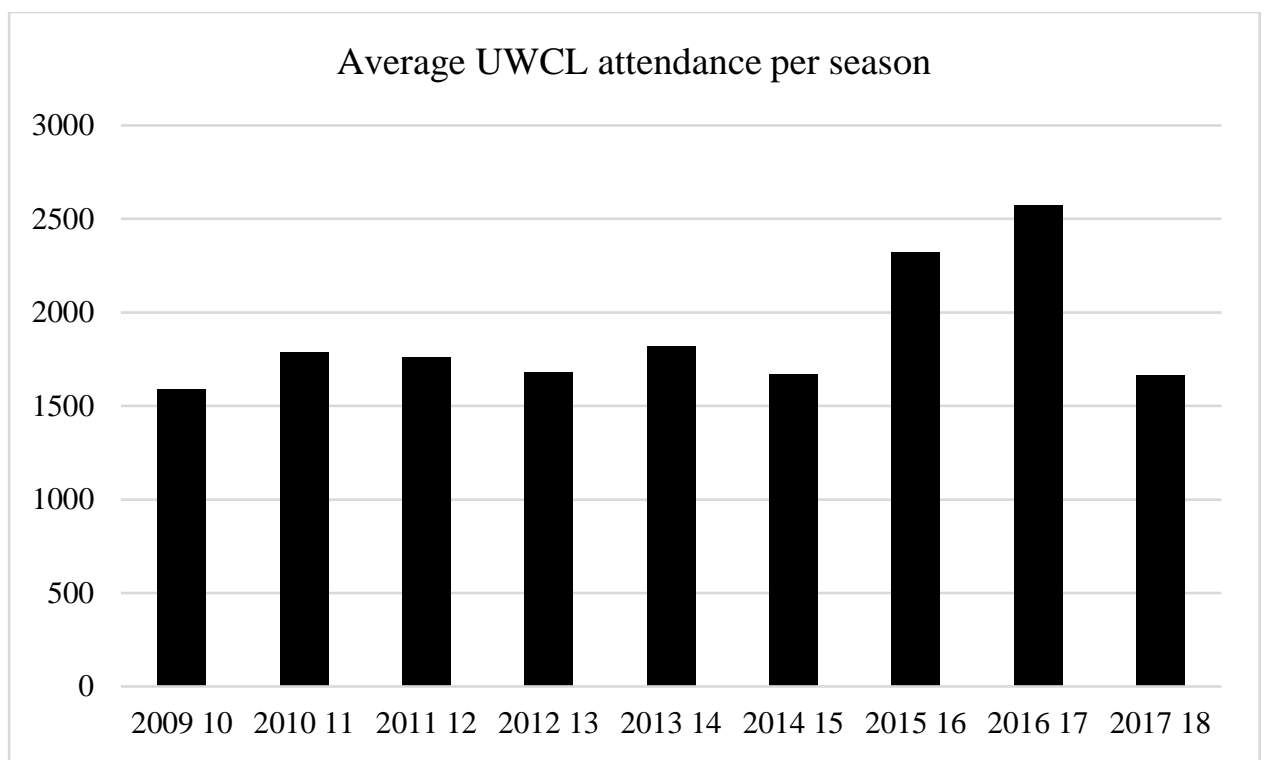

Figure 1. Average UWCL attendance per season. 
Table 3. Attendance for UWCL matches.

\begin{tabular}{|c|c|c|c|c|}
\hline & RE & & FE & \\
\hline Recent performance home team & $.28(.21)$ & & $.29(.22)$ & \\
\hline Recent performance away team & $.16(.13)$ & & $.18(.13)$ & \\
\hline Population & $-.01(.09)$ & & Omitted & \\
\hline Income home team & $-.16(.14)$ & & $.50(.71)$ & \\
\hline Income away team & $.00(.02)$ & & $.00(.02)$ & \\
\hline Distance & $-.04(.03)$ & & $-.03(.03)$ & \\
\hline Same country & $.16(.12)$ & & $.14(.12)$ & \\
\hline Weekend & $-.01(.11)$ & & $-.02(.11)$ & \\
\hline Temperature & $.01(.00)$ & $*$ & $.01(.00)$ & * \\
\hline Rain & $-.02(.06)$ & & $-.00(.06)$ & \\
\hline Uncertainty of outcome & $.47(.16)$ & $* * *$ & $.50(.16)$ & $* * *$ \\
\hline Competitive intensity & $-.02(.01)$ & $*$ & $-.02(.01)$ & $*$ \\
\hline Ownership home team & $.06(.37)$ & & Omitted & \\
\hline Big-5 home team & $-.13(.49)$ & & Omitted & \\
\hline Integrated and Big-5 home team & $.14(.47)$ & & Omitted & \\
\hline Ownership away team & $.08(.07)$ & & $.09(.07)$ & \\
\hline Big-5 away team & $.13(.08)$ & & $.13(.07)$ & $*$ \\
\hline Integrated and Big-5 away team & $.29(.11)$ & $* * *$ & $.28(.10)$ & $* * *$ \\
\hline Group stage & Ref. & & Ref. & \\
\hline 32-stage & $.86(.15)$ & $* * *$ & $.84(.15)$ & $* * *$ \\
\hline 16-stage & $.86(.20)$ & $* * *$ & $.85(.19)$ & $* * *$ \\
\hline Quarter & $1.44(.22)$ & $* * *$ & $1.42(.22)$ & $* * *$ \\
\hline Semi & $1.53(.23)$ & $* * *$ & $1.51(.23)$ & $* * *$ \\
\hline 200910 & $-.09(.21)$ & & $-.07(.21)$ & \\
\hline 201011 & Ref. & & Ref. & \\
\hline 201112 & $.37(.15)$ & $* *$ & $.33(.15)$ & $* *$ \\
\hline 201213 & $.23(.16)$ & & $.18(.18)$ & \\
\hline 201314 & $.32(.20)$ & & $.24(.22)$ & \\
\hline 201415 & $.33(.19)$ & $*$ & $.20(.21)$ & \\
\hline 201516 & $.49(.16)$ & $* * *$ & $.36(.20)$ & $*$ \\
\hline 201617 & $.50(16)$ & $* * *$ & $.33(.19)$ & $*$ \\
\hline 201718 & $.20(.17)$ & & $.04(.20)$ & \\
\hline Constant & $6.49(1.17)$ & $* * *$ & $-.07(7.16)$ & \\
\hline
\end{tabular}




\begin{tabular}{|c|c|c|}
\hline & $\mathrm{RE}$ & FE \\
\hline Home team & No & Yes \\
\hline Home country & Yes & No \\
\hline Within & .45 & .45 \\
\hline Between & .72 & .17 \\
\hline Overall & .62 & .30 \\
\hline Observations & 554 & 554 \\
\hline Groups & 90 & 90 \\
\hline
\end{tabular}


Table 4. Alternative models with Win probability for the home team, and alternatively with and without uncertainty of outcome.

\begin{tabular}{|c|c|c|c|c|c|c|c|c|}
\hline & $\mathrm{RE}$ & & $\mathrm{RE}$ & & FE & & $\mathrm{FE}$ & \\
\hline $\begin{array}{l}\text { Recent performance home } \\
\text { team }\end{array}$ & $.28(.22)$ & & $.29(.22)$ & & $.28(.22)$ & & $.29(.22)$ & \\
\hline Recent performance away team & $.15(.13)$ & & $.16(.13)$ & & $.18(.13)$ & & $.19(.13)$ & \\
\hline Population & $-.00(.08)$ & & $-.01(.09)$ & & Omitted & & Omitted & \\
\hline Income home team & $-.16(.14)$ & & $-.16(.14)$ & & $.50(.71)$ & & $.50(.71)$ & \\
\hline Income away team & $.00(.02)$ & & $.00(.02)$ & & $-.00(.02)$ & & $.00(.02)$ & \\
\hline Distance & $-.04(.03)$ & & $-.04(.03)$ & & $-.03(.03)$ & & $-.03(.03)$ & \\
\hline Same country & $.17(.12)$ & & $.16(.12)$ & & $.14(.12)$ & & $.14(.12)$ & \\
\hline Weekend & $-.03(.12)$ & & $-.02(.12)$ & & $-.02(.12)$ & & $-.01(.12)$ & \\
\hline Temperature & $.01(.00)$ & $*$ & $.01(.00)$ & $*$ & $.01(.00)$ & $* *$ & $.01(.00)$ & $*$ \\
\hline Rain & $-.02(.06)$ & & $-.02(.06)$ & & $-.01(.06)$ & & $-.00(.06)$ & \\
\hline Uncertainty of outcome & & & $.46(.38)$ & * & & & $.58(.37)$ & \\
\hline Competitive intensity & $-.02(.01)$ & $*$ & $-.02(.01)$ & $* *$ & $-.02(.01)$ & $*$ & $-.02(.01)$ & $*$ \\
\hline Win probability home team & $1.24(.60)$ & $* *$ & $-.05(1.20)$ & & $1.43(.60)$ & $* *$ & $-.22(1.15)$ & \\
\hline Win probability ${ }^{2}$ home team & $-1.53(.61)$ & $* * *$ & $.00(1.38)$ & & $-1.66(.60)$ & $* * *$ & $.28(1.33)$ & \\
\hline Ownership home team & $.03(.37)$ & & $.05(.37)$ & & Omitted & & Omitted & \\
\hline Big-5 home team & $.58(.80)$ & & $.60(.80)$ & & Omitted & & Omitted & \\
\hline $\begin{array}{l}\text { Integrated and Big-5 home } \\
\text { team }\end{array}$ & $.16(.47)$ & & $.15(.47)$ & & Omitted & & Omitted & \\
\hline Ownership away team & $.08(.07)$ & & $.08(.07)$ & & $.09(.07)$ & & $.09(.07)$ & \\
\hline Big-5 away team & $.11(.07)$ & & $.12(.07)$ & & $.13(.07)$ & $*$ & $.13(.07)$ & $*$ \\
\hline $\begin{array}{l}\text { Integrated and Big-5 away } \\
\text { team }\end{array}$ & $.28(.12)$ & $* * *$ & $.28(.12)$ & $* *$ & $.29(.11)$ & $* *$ & $.28(.11)$ & $* *$ \\
\hline Group stage & Ref. & & Ref. & & Ref. & & Ref. & \\
\hline 32-stage & $.83(.17)$ & $* * *$ & $.84(.17)$ & $* * *$ & $.83(.17)$ & $* * *$ & $.85(.17)$ & $* * *$ \\
\hline 16-stage & $.82(.21)$ & $* * *$ & $.84(.22)$ & $* * *$ & $.84(.21)$ & $* * *$ & $.86(.22)$ & $* * *$ \\
\hline Quarter & $1.40(.25)$ & $* * *$ & $1.42(.25)$ & $* * *$ & $1.42(.25)$ & $* * *$ & $1.44(.25)$ & $* * *$ \\
\hline Semi & $1.49(.25)$ & $* * *$ & $1.51(.26)$ & $* * *$ & $1.51(.25)$ & $* * *$ & $1.52(.26)$ & $* * *$ \\
\hline 200910 & $-.09(.21)$ & & $-.09(.21)$ & & $-.07(.21)$ & & $-.07(.21)$ & \\
\hline 201011 & Ref. & & Ref. & & Ref. & & Ref. & \\
\hline 201112 & $.37(.15)$ & $* *$ & $.37(.15)$ & $* *$ & $.33(.15)$ & $* *$ & $.33(.15)$ & $* *$ \\
\hline 201213 & $.23(.16)$ & & $.23(.16)$ & & $.17(.18)$ & & $.18(.18)$ & \\
\hline 201314 & $.32(.20)$ & & $.32(.20)$ & & $.23(.22)$ & & $.24(.22)$ & \\
\hline 201415 & $.33(.19)$ & $*$ & $.33(.19)$ & $*$ & $.20(.22)$ & & $.20(.21)$ & \\
\hline
\end{tabular}




\begin{tabular}{|c|c|c|c|c|c|c|c|c|}
\hline & $\mathrm{RE}$ & & RE & & FE & & $\mathrm{FE}$ & \\
\hline 201516 & $.49(.17)$ & $* *$ & $.49(.17)$ & $* *$ & $.35(.20)$ & $*$ & $.36(.20)$ & * \\
\hline 201617 & $.50(.16)$ & $* *$ & $.50(.16)$ & $* *$ & $.33(.19)$ & * & $.33(.19)$ & * \\
\hline 201718 & $.20(.18)$ & & $.20(.18)$ & & $.04(.20)$ & & $.04(.20)$ & \\
\hline Constant & $\begin{array}{l}6.80 \\
(1.17)\end{array}$ & $* *$ & $\begin{array}{l}6.53 \\
(1.18)\end{array}$ & $* * *$ & $.18(7.15)$ & & $-.16(7.14)$ & \\
\hline Home team & No & & No & & Yes & & Yes & \\
\hline Home country & Yes & & Yes & & No & & No & \\
\hline Within & .45 & & .45 & & .45 & & .45 & \\
\hline Between & .73 & & .72 & & .17 & & .17 & \\
\hline Overall & .62 & & .62 & & .30 & & .30 & \\
\hline Observations & 554 & & 554 & & 554 & & 554 & \\
\hline Groups & 90 & & 90 & & 90 & & 90 & \\
\hline
\end{tabular}

Note: The dependent variable is Ln Attendance; * $\mathrm{p}<.10 ; * * \mathrm{p}<.05 ; * * \mathrm{p} \leq .01$. Season 2010/11 as reference category for seasonal dummies. Group stage as reference category for stage of the competition dummies. Coefficients (and standard errors) are displayed in the first columns of each model. Robust standard errors are clustered by home team. 